"Financial cost implications of inaccurate extraction of transactional data in large African power distribution utility"

\begin{tabular}{|c|c|c|}
\hline AUTHORS & \multicolumn{2}{|l|}{$\begin{array}{l}\text { Patient Rambe } \\
\text { Johan Bester }\end{array}$} \\
\hline ARTICLE INFO & \multicolumn{2}{|c|}{$\begin{array}{l}\text { Patient Rambe and Johan Bester (2016). Financial cost implications of } \\
\text { inaccurate extraction of transactional data in large African power distribution } \\
\text { utility. Problems and Perspectives in Management, 14(4), 112-123. } \\
\text { doi:10.21511/ppm.14(4).2016.14 }\end{array}$} \\
\hline DOI & \multicolumn{2}{|c|}{ http://dx.doi.org/10.21511/ppm.14(4).2016.14 } \\
\hline RELEASED ON & \multicolumn{2}{|l|}{ Wednesday, 14 December 2016} \\
\hline JOURNAL & \multicolumn{2}{|c|}{ "Problems and Perspectives in Management" } \\
\hline FOUNDER & \multicolumn{2}{|c|}{ LLC "Consulting Publishing Company "Business Perspectives" } \\
\hline & & $\begin{array}{l}= \pm= \\
= \pm=\end{array}$ \\
\hline NUMBER OF REFERENCES & NUMBER OF FIGURES & NUMBER OF TABLES \\
\hline 0 & 0 & 0 \\
\hline
\end{tabular}

(C) The author(s) 2023. This publication is an open access article. 
Patient Rambe (South Africa), Johan Bester (South Africa)

\title{
Financial cost implications of inaccurate extraction of transactional data in large African power distribution utility
}

\begin{abstract}
In view of the increasingly competitive business world, prudent spending and cost recovery have become the driving forces for the optimal performance of large public organizations. This study, therefore, examined the cost-effectiveness of a Large Energy Utility (LEU) in a Southern African country by exploring the relationship between extraction of transactional customer data (that is, data on the servicing and repairing energy faults) and the Utility's recurrent expenditure (especially its technicians' overtime bill). Using data mining, a large corpus of the LEU Area Centre (AC) data was extracted to establish the relationship between transactional customer data extraction including capture and the financial cost of the LEU (e.g., recurrent expenditure on overtime bill). Results indicate that incorrect extraction and capturing of transactional customer service data has contributed significantly to the LEU's escalating overtime wage bill. The data also demonstrate that the correct extraction and capturing of transactional customer service data can positively reduce the financial costs of this LEU. The paper demonstrates one of the few attempts to examine the effects of correct data extraction and capture on the financial resources of a struggling large public energy utility. Using the Resource Based Theory, the study also demonstrates how technicians' feedback on incorrect transactions enhances the measurement of inaccurate transactional data albeit a burgeoning overtime wage bill incentives.
\end{abstract}

Keywords: Large Energy Utility, inaccurate transactional data extraction, financial costs, Resource Based View. JEL Classification: L94, L97, C8.

\section{Introduction}

The LEU was established as a state owned company responsible for the regulation, controlling and running of an African country's energy industry (Large Energy Utility, 2013a) ${ }^{1}$. Since its inception, the LEU has grown into a strong utility which is able to fulfil most of its country's energy requirements (Large Energy Utility, 2015a). Even though LEU is regarded as a monopoly, the country's cabinet approved private sector participation in the energy industry through its decision to allow Alternative Energy Suppliers (AES) to supply a share of the energy needed for the nation (Energy Department, 2015; Energy department, 2011b, p. 21).

While LEU's predicaments are manifold, one apparent constraint is of a financial nature. The financial hurdles of LEU can be attributed to the tariff increase allowed by its Energy Regulator (ER) which were lower than the LEU's projected financial obligations. This resulted in a significant financial shortfall for the LEU's 5 year budget period (Large Energy Utility, 2015e, p. 16), which necessitated the country's government to provide

(C) Patient Rambe, Johan Bester, 2016.

Patient Rambe, Department of Business Support Studies, Central University of Technology, South Africa.

Johan Bester, Department of Business Support Studies, Central University of Technology, South Africa.

1 To protect the identity of this national energy utility, which is currently under severe economic strain and political controversy, the leadership of this organization required that we mask the name of this institution. For this reason, all the sources that make reference to the identity of the institution and the regulatory regime of this institution were also intentionally masked as required by the senior authorities of this organization. conditional financial assistance to the LEU. The conditions coupled to the assistance, however, necessitate that some serious savings must be achieved by the LEU in its latest 5 year budget period (Treasury, 2015). The irony, however, is that savings might be inconceivable in view of the LEU's incumbent fiscal position. For instance, the LEU Business Overview Report of 2014-2015 reveals that during this reporting period, primary energy production costs increased, whilst sales declined and customer debt increased (Large Energy Utility, 2015e, p. 39). Given these financial woes, realizing savings by selling more energy or decreasing the input costs to source the energy would be insurmountable for the LEU. The logical corporate position, therefore, would be to emphasize cost reduction on current support operations and efficient service provision.

A reasonable proxy for assessing cost reduction and generation of saving reserves at the LEU could be unravelling the mechanisms of transactional data (that is, data generated from the travelling to, attending, servicing and repairing the LEU's customer queries) to determine warranted (genuine) and unnecessary service-related expenditure on such operations. For every customer query related to a loss of energy supply, transactional data are captured at the LEU Contact centre. While it is critical for the LEU technicians to respond to customer queries to restore the supply and stability of energy to maintain revenue from existing customers, such operations contribute to the escalation of recurrent expenditure. For this reason, it is incumbent upon the LEU technicians to respond exclusively to genuine customer queries caused by 
faulty LEU equipment rather than faulty customer equipment or human error. Due to the LEU's current lack of knowledge on the financial implications of incorrect extraction and documentation of transactional customer data, it is plausible that the LEU could be missing an important opportunity to reduce the cost of its support operations by ceasing to respond to unwarranted or disingenuous customer requests for services and repairs. As such, a reconciliation of transactional customer service data and all recurrent expenditure on loss of supply queries could help to determine the cost contribution of responding to genuine customer queries and eliminate unwarranted transactional costs of the LEU. The implementation of such interventions to prevent incorrect transactional customer data could significantly improve the savings reserves required of the LEU within the allotted 5 year period. The competition from AESs in the foreseeable future also necessitates the LEU to run cost effective energy transactions and services, to ensure sustainability and a competitive advantage in the energy supply industry.

\section{Research questions}

In view of the foregoing discussion on generating appropriate transactional customer call data to reduce unwarranted costs of servicing and repairs, enhancing effective service delivery and increasing saving reserves within the 5 year period, we wondered about the nature and accuracy of transactional customer call data and the relationship of such data with the LEU's recurrent expenditure. For this reason, we posed the following critical questions:

1. What is the nature and extent of accuracy of transactional customer data of the LEU Province A?

2. What is the relationship between accuracy of transactional customer data and recurrent expenditure (especially overtime wage bill) of the LEU Province A?

\section{Background}

Energy is regarded as a pivotal component and enabler of mining, industrial, commercial and domestic activities that drive economic growth opportunities and enhance decent living for all African citizens. By the same token, the Republic of the African country wherein LEU resides' Expansion Plan (EP) (which aims to eliminate poverty and reduce inequality) portrays energy as an important component of a development framework that would assist society in adopting a decent standard of living (State Commission, 2015, p. 31).
Mindful of this profound importance of energy for human development and survival, it is unsurprising that the government is the sole shareholder of LEU that directs this organization's actions to ensure the achievement of its strategic objectives (Large Energy Utility, 2013b).

The financial woes of LEU should be conceived in light of the historical trajectory of bestowing energy services to the nation and the burgeoning customer base. By means of an Energizing Programe, access to energy for the country's households was raised from only $40 \%$ in 1987 to $85.4 \%$ in 2013. The surging increase in connected households, which depicts an annual growth of $3.09 \%$ (Statistics of Country, 2014, p. 16) contributes to a strain in energy services and the financing of energy service provision.

\section{Literature review}

3.1. Rising energy tariffs. Since high energy tariffs are a barrier to entry for many stakeholders, the provision of energy at affordable cost (to those with low purchasing power) (Energy Department, 1998, p. 3 ) and free of charge or at a minimum cost for certain classes of end users cannot be overemphasised (Energy Department, 2011a; State Commission, 2015; MCD \{Masked\}, 2009). Unfortunately, LEU's increases in energy prices started to surpass the country's inflation rate in recent years, resulting in evasion of payment and reduced compliance from customers, which negatively impacted LEU's revenue generation. Furthermore, LEU operates in a highly regulated legislative environment that complicate the generation of optimal profit. For instance, the ER only approved half of the requested energy tariff increase proposed by LEU, which resulted in a significant financial shortfall for its latest 5 year budget period (Large Energy Utility, 2015e, p. 16). The shortfall is a consequence of ER's task of balancing the interests of energy producers and consumers, whilst taking into consideration the achievement of the EP to address poverty, inequality and unemployment against the backdrop of the continuing global economic recession (ED, 2013, pp. 5, 7-8).

The country's government decided to financially assist LEU on the condition that it achieves significant savings by the end of its 5 year budget period (Treasury, 2015). LEU has been called upon to embark on several initiatives to address the shortfall, increase productivity and improve overall operations (Large Energy Utility, 2015e, p. 17). It is in view of increasing the liquidity, saving reserves and reducing avoidable expenditure in LEU that the current study should be conceived. 
3.2. Data types and the impact of data quality on business. The term "data" necessities a definition if transactional data is to be fully comprehended. Data are defined as "a collection of unorganized facts", whereas information is described as "data that are organized, have meaning and are useful" (G Shelly, 2012, p. 4). Data can be classified as an asset when it is important for an organization's success (Borek et al., 2014, pp. 6-7) and, consequently, organizations are leveraging data and data quality to increase current customer value and to attain new customers (Experian data quality, 2015, p. 4). Although this study deals with transactional data, these data are implicated in other forms of data, which also require definition. These data categories range from master, transactional, reference to historical data. Master data relate to key business information about customers, assets, products, etc., and does not change frequently. Transactional data describe a business event that happens at a certain time, is normally very capricious and often refers to master data (Borek et al., 2014, pp. 6-7). Reference data are used to categorize master and transactional data; they consist of a set of allowed values and are mostly static and slow changing (Chen et al., 2013, pp. 3-5). Historical data include master, transactional and reference data and refer to past transactions, which are retained for historical or legal purposes (Borek et al., 2014, pp. 6-7).

When a forced outage (that is, an interruption in energy supply due to a problem with LEU's network or equipment) occurs, LEU's process of restoring energy supply involves the interfacing of transactional, master and reference data. Whenever an LEU customer reports a forced outage/energy supply problem (ESP), master data are referenced to find the customer detail and location. Transactional data such as the fault description, directions to the fault and time of call are, then, captured. By means of interpretation, the call centre agent categorizes the request (based on the captured transactional data) as an ESP by selecting reference data. These master, transaction and reference data, ultimately, form a transaction which will invoke a process to fix an ESP. After the ESP is fixed, the transaction will become historical data. There are costs associated with each transaction, as LEU has to use its resources (personnel, vehicles, time, equipment and spares) to fix the ESP according to ER's rules. Whenever there is poor extraction of transactional data, it can result in unnecessary consumption of LEU's resources, which hampers its efforts to achieve monetary savings.

The generation of poor quality data may result in difficulties in locating needy customers, inordinate delays in dealing with their queries and general frustration with the services the organization provides to customers. As such, an organization's reliance on poor customer data may result in customer dissatisfaction with services, unwarranted increases in costs, compromized decision making and lowered job satisfaction (Sadiq, 2013, p. 77). While the Global data quality research of 2015 found out that generating data of highest quality could increase the profits of an organization by an average of $15 \%$, the majority of companies surveyed (about 92\%) found it challenging to generate high data quality (Experian data quality, 2015, p. 4) due to the involvement of tangible and intangible components. As such, it is estimated that U.S. businesses loses more than $\$ 600$ billion a year due to problems with data quality (Eckerson, 2002, p. 3). It is, therefore, imperative to investigate the costs of poor data quality in order to have an understanding of the effect it has on a company's bottom line (Wang et al., 2005, p. 6). Existing literature tends to address the impacts and costs of poor quality data, the different strategies and tools available to correct data and how to determine the return on investment generated by an improvement of data quality (Freeform dynamics, 2013a; Freeform dynamics, 2013b). The data implied are typically master data, for example, customer data, stock details, supplier data, etc. Transactional data quality costs, however, are less frequently implied, especially when generated by resource constrained organizations in African developing countries (Freeform dynamics, 2013a; Hassanien, et al., 2015, p. 398; Haug, et al., 2011; Reid \& Catterall, 2005).

\section{Theoretical framework}

Resource Based View (RBV) has evolved into the Resource Based Theory (RBT) (Kozlenkova, Samaha and Palmatier, 2014, p. 3; Nothnagel, 2008, pp. 19-20) and will be drawn upon to study the influence of inaccurate transactional data on LEU's financial position, particularly its recurrent expenditure. RBT enables the proponent thereof to view an organization as a collection of tangible and intangible resources that can be exploited by processes, systems and structures to obtain a strategic competitive advantage (Kozlenkova, Samaha and Palmatier, 2014, pp. 2-12; McIvor, 2005 , p. 5) When correctly captured, documented and retrieved, transactional, master and reference data on customer queries can be harnessed as an ideal strategic resource to effectively identify the geographical location of the customer, the nature of the fault and the appropriate technician or engineer to be deployed to address such queries. Mindful of the AES that operate in the country in collaboration 
with LEU, the generation of accurate transactional, master and reference data could be invaluable for the selection and allocation of appropriate additional resources (transport to customer location, technical equipment and time resources) needed to locate and resolve customer queries timeously and efficiently. The capturing, documentation and retrieval of accurate data, therefore, can be deployed as a strategic resource by LEU to:

- Satisfy customer needs through resolution of queries.

- Enhance revenue generation from customers through timeous payment of tariffs and reduced non-payment of energy tariffs as customers experience value for money.

- Broaden LEU's customer base as newly connected customers contribute to LEU's fiscal base.

- Increase customer confidence in LEU's energy supply services.

- Expand existing energy infrastructure through the bankrolling of LEU's current expansion projects.

- Reduce LEU's dependence on government financial assistance.

Collectively, the aforementioned benefits contribute directly to the optimization of LEU's competitive advantage over its rivals.

Conversely, the generation of inaccurate transactional, master and reference data on customer location and type of technical faults could result in unwarranted expenditure as multiple resources (personnel, transport, equipment and time) are deployed to address hoax queries, faults of the customers' making or locate a customer in an unidentified location. A consequence of such a scenario is difficulty in locating customers, leading to resource wastage, delays in query resolution, reduced customer confidence in LEU energy services, increased delays in tariff payments or in non-payments of tariffs and stagnant customer base as new customers are not added to the grid. In cases where LEU technicians respond to "hoax calls," the eventuality is a burgeoning recurrent expenditure (through unwarranted wage and overtime bill), reduced savings, inefficient use of critical but limited resources and a loss of competitive advantage by LEU. Our view is that efficiency in LEU (i.e., delivering the best service at the lowest cost (Collin, 2006, p. 60) can be enhanced by identifying and measuring the cost of instances where inaccurate transactional data capturing and interpretation resulted in the erroneous invoking of the process to fix an ESP.

\section{Methodology}

A critical case study was undertaken to determine the financial cost implications of inaccurate transactional data on LEU Province A Area Centres (AC). A critical case study is considered appropriate where the researcher cannot manipulate or control events (Cohen, et al., 2011, p. 290) and has the intention to support, challenge or extend propositions specified by an adopted/applied theory (Farquhar, 2012, p. 40). Data were collected through documentary research to determine the financial cost of servicing and maintenance as a result of incorrect extraction and documentation of data. The documentary research involved an examination of:

5.1. LEU call and data quality on ESP faults. The latest available Group Customer Service Workforce Optimization Report was used to identify possible call and transactional data quality issues related to ESP calls. The National results of the inbound service types related to ESP were referenced for this purpose. The overall score for ESP call and data quality is calculated by evaluating call professionalism when answering a call, whether all the steps were followed correctly to: identify a customer, to interpret his fault symptoms, to send the fault to the correct department and lastly if the call was concluded professionally. The fact that all these factors are combined and represented within the score does not allow a direct extraction of transactional data quality. Call content which is related to transactional data quality comprises $70 \%$ of the total score (Large Energy Utility, 2015d, pp. 1-2, 5-6) and, as a result, most of the scoring is related to transactional data quality.

\subsection{LEU data on ESP faults and a customer fault} indicator signifying inaccurate transactional data. Oracle database tables related to LEU's enterprise asset management system were queried with sequential query language (SQL) to extract workorders (instructions to perform work) related to forced outages/ESP from 1 April 2003 to 31 March 2015. The data were normalized in Excel 2010 by removing incomplete records. The Haversine formula (Afalciano, 2014) was used to calculate a direct line distance between the coordinates of a customer's location and the AC responsible to service a customer. The hypothesis of a direct line was used to ensure consistent measurement and uniformity across various queries considered. Travel time was calculated on distance to infer travel cost by means of the staff's hourly remuneration cost, as well as overtime rules applied to travel time. As there were limited historical data available to determine actual work time, only the travel time was used to determine work time for a workorder. 
Although the method adopted provides a good estimate for comparing workorder overtime costs in consecutive financial years, the costs are not actual costs from the financial system, since a long history of labor transactions for forced outage work performed is not available. Each workorder has a feedback loop that allows a technician to mark/flag it as a customer fault after he arrived on site to perform the requested work. This functionality allowed the researchers to differentiate between valid ESP and customer side fault (caused by incorrect transactional data from the contact centre) workorders.

\subsection{LEU data on wage bills for maintenance staff.} Oracle database tables related to LEU's enterprise asset management system was queried with SQL to extract labor transactions for the financial year 20142015 related to forced outages/ESP. The data were manipulated in Excel 2010 with LEU's overtime rules to accurately calculate costs. The workorder numbers linked to the labor transactions were cross referenced with the workorder numbers related to customer faults to allow an accurate costing for the period queried.

\section{Limitations of data sources}

While the study employed reasonable proxies for determining the costs of addressing ESP callouts, some caveats are necessary as readers draw on the findings from the current study. To this effect, our results should be interpreted in view of the current limitations of the data sources we employed. These limitations are discussed in subsequent sections of this study.

6.1. Data availability. ESP call quality report of January 2015 was used as the final score for 20142015 was not available. Actual labor cost history from 2003 to 2015 was lacking thus another model was applied to forced outage workorders to determine labur costs. Actual labor hour data for 2014-2015 were modelled with overtime rules to improve labor cost accuracy. Hourly rates of the lowest technical staff were utilized to determine labor cost, as LEU was not at liberty to reveal each technician's hourly remuneration.

\subsection{Accuracy on the usage of customer side fault} indicator. The usage of customer side fault indicator was assumed to have been used correctly in all instances.

\section{Presentation of findings}

7.1. ESP Transactional call quality. A customer call can be routed to any of LUE's 7 regional call centres. Therefore, the transactional call quality of all call centres combined (National) should be considered when analysing the ESP transactional call quality. Table 1 exhibits a summary of the quality assurance results for the different regional contact centres on incoming calls received/inbound for; accounts, prepaid meters (APM), applications, terminations of supply (ATS), disconnections and credit extensions (DCE), energy supply problems (ESP), energy efficiency service (EES) and other interactions logged (OIL). For the purpose of this study, only the ESP score is important, as it comprises of phone etiquette $(30 \%)$ and transactional data quality $(70 \%)$ related to forced outages/ESP. The score of customer calls related to an ESP was $75 \%$ for the 2014-2015 financial year of LEU. There is, thus, a possible error margin of $25 \%$ on workorders that were generated from this data.

Table 1. ESP call quality

\begin{tabular}{|l|c|c|c|c|c|c|c|c|c|}
\hline \multicolumn{7}{|c|}{$\begin{array}{c}\text { AVERAGE RESULTS } \\
\text { FOR INBOUND SERVICE TYPES ASSESSED } \\
\text { (85\% TARGET) }\end{array}$} \\
\hline & APM & ATS & $\begin{array}{c}\text { ATS } \\
\text { move } \\
\text { in }\end{array}$ & $\begin{array}{c}\text { ATS } \\
\text { move } \\
\text { out }\end{array}$ & DCE & ESP & EES & OIL & UNSPECIFIED \\
\hline REGION 1 & $58 \%$ & $82 \%$ & $86 \%$ & $65 \%$ & $84 \%$ & $72 \%$ & & & $92 \%$ \\
\hline REGION 2 & $88 \%$ & $84 \%$ & & & $88 \%$ & $80 \%$ & & & \\
\hline REGION 3 & $56 \%$ & $60 \%$ & $0 \%$ & $80 \%$ & $32 \%$ & $66 \%$ & & $60 \%$ & \\
\hline REGION 4 & $80 \%$ & $86 \%$ & & & $86 \%$ & $74 \%$ & & & $96 \%$ \\
\hline REGION 5 & $90 \%$ & & & & & $78 \%$ & & & $76 \%$ \\
\hline REGION 6 & $88 \%$ & $89 \%$ & & & $93 \%$ & $82 \%$ & & & $71 \%$ \\
\hline REGION 7 & $70 \%$ & $78 \%$ & & & $73 \%$ & $72 \%$ & & & \\
\hline NATIONAL & $76 \%$ & $80 \%$ & $43 \%$ & $73 \%$ & $76 \%$ & $75 \%$ & & $60 \%$ & $84 \%$ \\
\hline
\end{tabular}


7.2. Workorders based on ESP transactional data over the past 12 years (different years and different years combined). According to the summary of the total workorder breakdown (see Table 2. Total workorder breakdown. Total workorder breakdown which is the total amount of workorders (valid ESP and customer faults combined) from the start of the analysis period fluctuated through stages of increases and decreases with the biggest decreases noted during the last three financial years. However, the amount of customer fault workorders (signifying incorrect transactional data) for the same period depicts a steady increase. As a result, the percentage that customer fault workorders contribute to the total amount of workorders depicts an increase, with the highest contribution of $19.2 \%$ in 2014-2015 (see Fig. 1). By isolating the overtime workorders only (see Fig. 2. \% customer fault comparison to valid ESP fault for overtime transactions) and repeating the analysis of the percentage contribution that customer faults makes to the total amount of workorders, the increased trend can be observed again, but the contribution of $15.9 \%$ in overtime only is less than normal time and overtime combined.

Table 2. Total workorder breakdown

\begin{tabular}{|c|c|c|c|}
\hline $\begin{array}{l}\text { Count of WO TOTAL } \\
\text { Row Labels }\end{array}$ & $\begin{array}{l}\text { Column Labels } \underset{ }{\square} \\
\text { IT Customer Fault }\end{array}$ & Valid ESP fault & Grand Total \\
\hline$\exists \quad$ PROVINCEA & 69374 & 643446 & 712820 \\
\hline 2003-2004 & 2994 & 60399 & 63393 \\
\hline $2004-2005$ & 2998 & 56642 & 59640 \\
\hline $2005-2006$ & 3152 & 54322 & 57474 \\
\hline $2006-2007$ & 3782 & 53963 & 57745 \\
\hline $2007-2008$ & 5066 & 57762 & 62828 \\
\hline 2008-2009 & 5450 & 58838 & 64288 \\
\hline $2009-2010$ & 5584 & 59184 & 64768 \\
\hline 2010-2011 & 6318 & 59856 & 66174 \\
\hline $2011-2012$ & 7176 & 61454 & 68630 \\
\hline $2012-2013$ & 8849 & 41952 & 50801 \\
\hline 2013-2014 & 8759 & 40115 & 48874 \\
\hline $2014-2015$ & 9246 & 38959 & 48205 \\
\hline Grand Total & 69374 & 643446 & 712820 \\
\hline
\end{tabular}

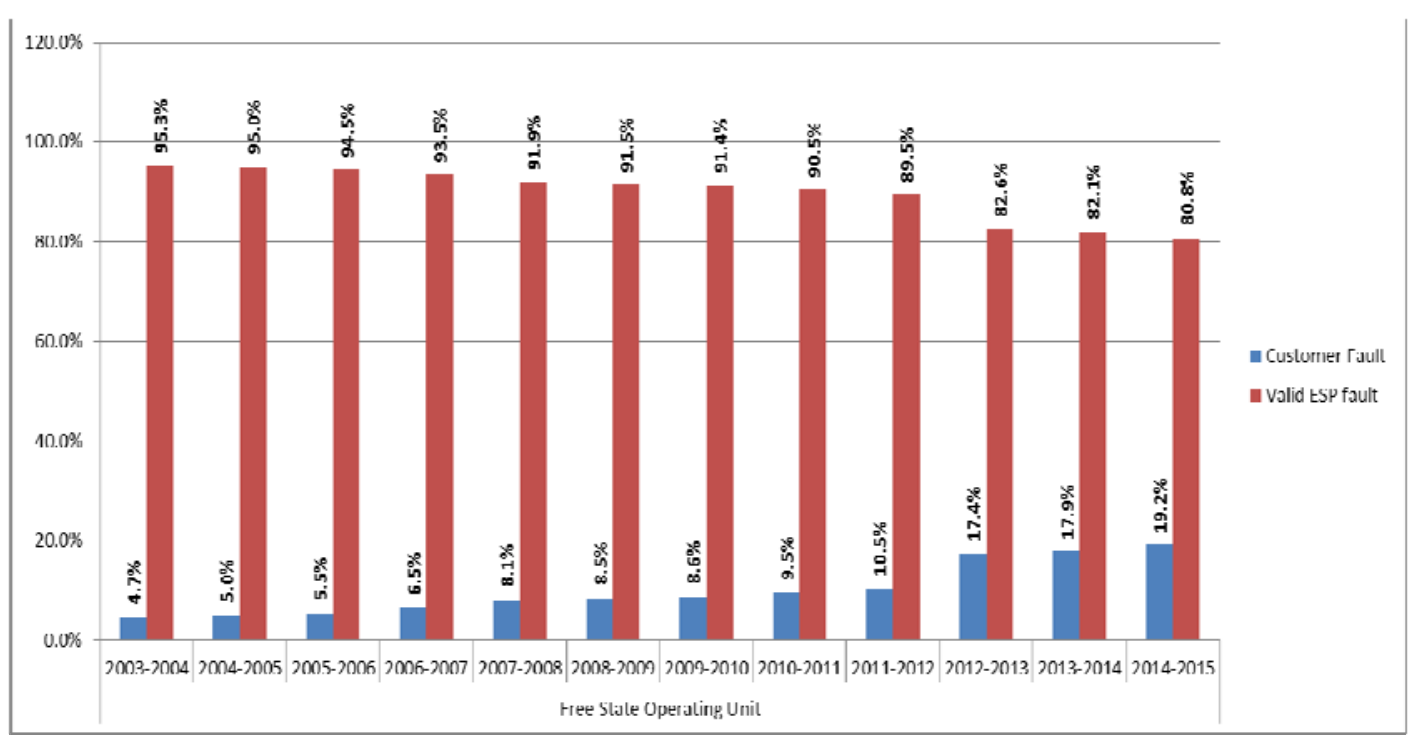

Fig. 1. \% customer fault comparison to valid ESP fault

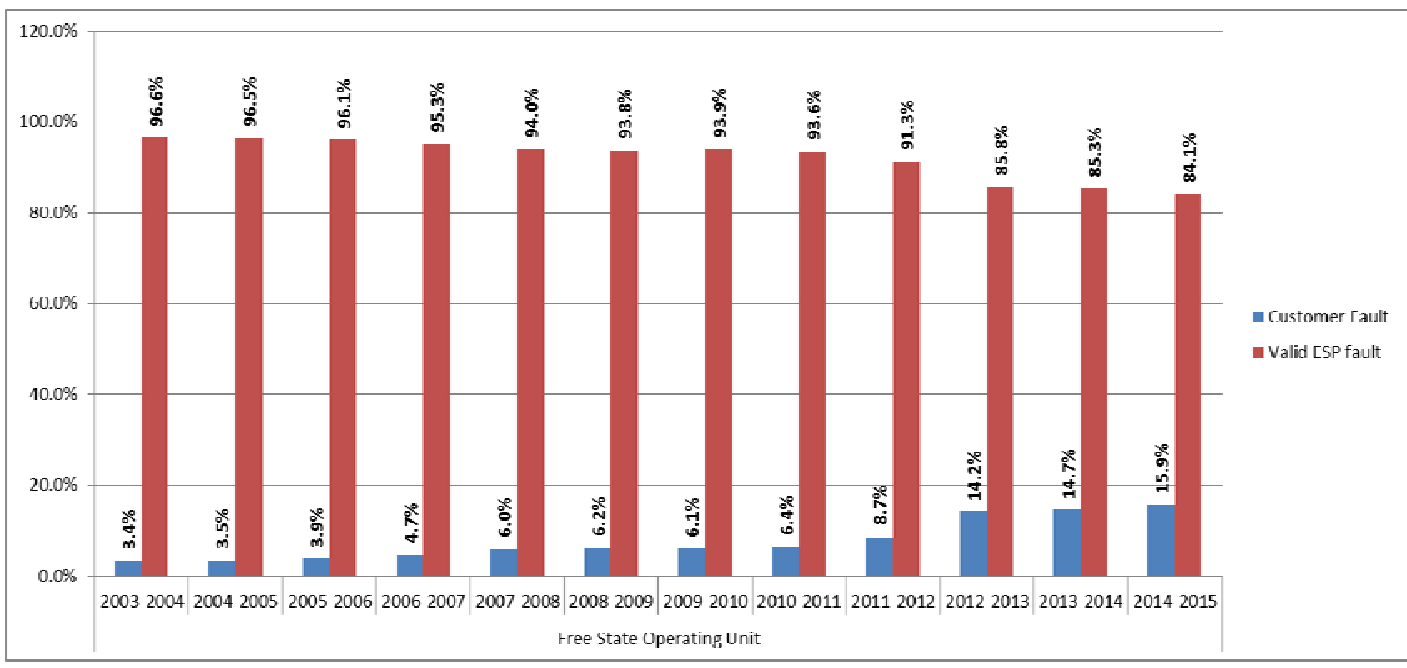

Fig. 2. \% customer fault comparison to valid ESP fault for overtime transactions 
An analysis of the overtime cost of customer side faults for a year on year comparison depicts a general increase in costs over each financial year, with exceptions in 2004-2005, 2009-2010 and 2013-2014. The yearly growth over the period analyzed indicates an average annual growth of $11 \%$ (see Figure 3 ).

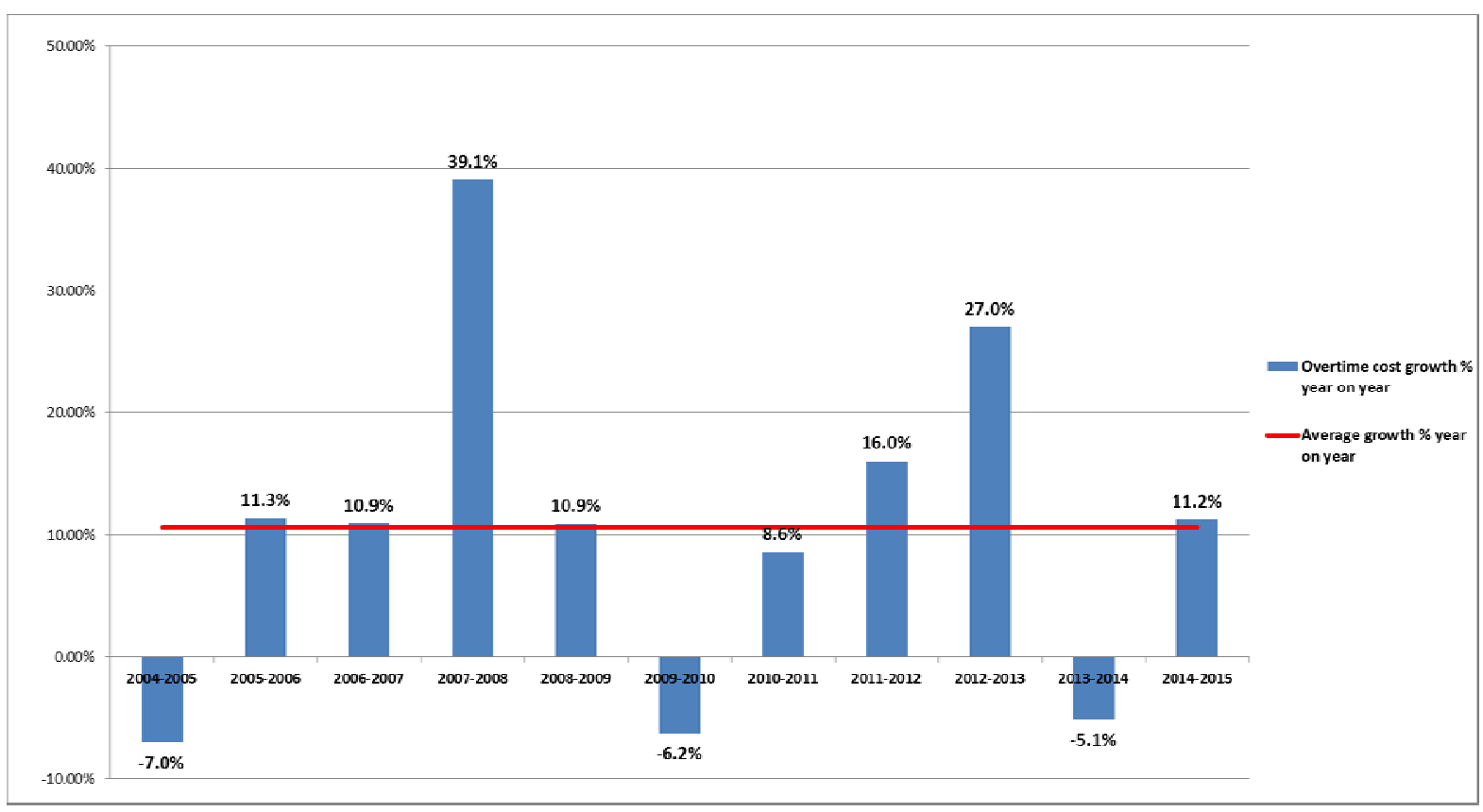

Fig. 3. Customer side faults overtime cost, year on year comparison

7.3. The ACs (in a typical year, e.g., 2014, and over the years). By comparing each AC's percentage contribution towards Province A's total overtime cost of customer side faults for 2014-2015 to the average for all financial years combined (see Figure 5), most AC's contribution display a similar trend for the periods under investigation. AC 4 and AC 19 are, however, exceptions to this observation, as their contributions in 2014 have a spike difference of over $2 \%$.

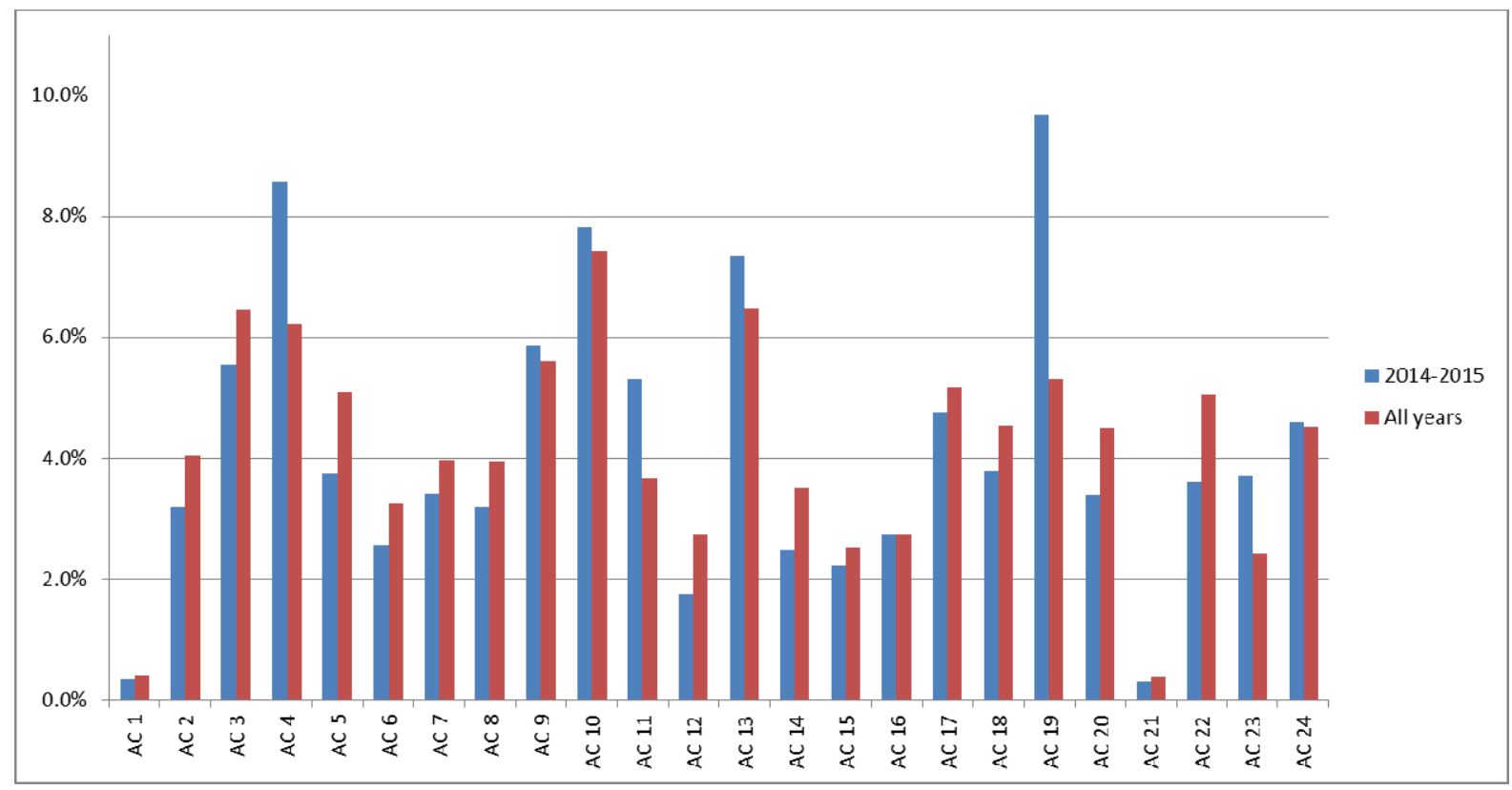

Fig. 4. \% contribution to total Province A overtime cost on customer faults

An analysis of each AC's contribution to the total overtime customer side faults and costs for the financial period 2014-2015 indicates an increase in the percentage cost contribution where there is a higher percentage contribution to the amount of customer faults (see Fig. 4). The correlation is, however, not direct, as AC 2, AC 7 and AC 9 ACs have a lower cost contribution (more than $1 \%$ ) in relation to their percentage of workorders than the other ACs. Conversely, AC 10, AC 19 and AC23 have a higher cost contribution (more than $1 \%$ ) in relation to their percentage of customer side faults, 
compared to other ACs. Each AC's individual profile of overtime percentage cost contribution by customer side faults compared to the percentage of overtime customer fault workorders of total workorders (see Fig. 6. Overtime: $\%$ customer side fault cost contribution vs \% customer side faults per $\mathrm{AC}$ for 2014-2015). The average cost contribution of all AC's customer side faults is $9.5 \%$ and the average percentage of all AC's customer side fault workorders is $15.9 \%$. A general trend exists where an increase in the percentage of customer side faults is followed by an increase in the percentage overtime cost contribution by customer side faults with exceptions in $\mathrm{AC}$ 4, AC 9, AC 21, AC 23 and $\mathrm{AC} 24$.

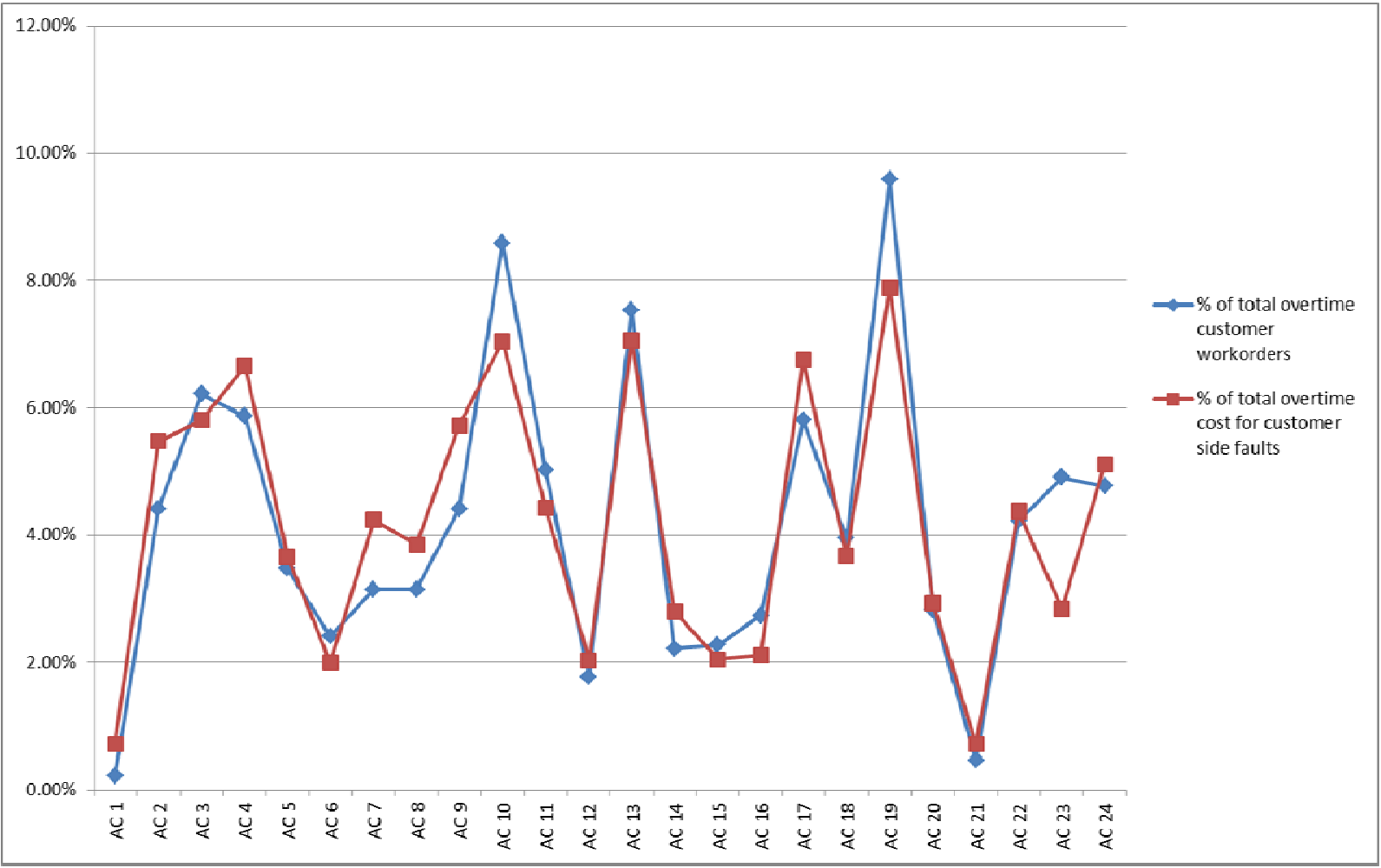

Fig. 5. Total overtime cost (primary $Y$ axis) vs amount of customer faults for period 2014-2015

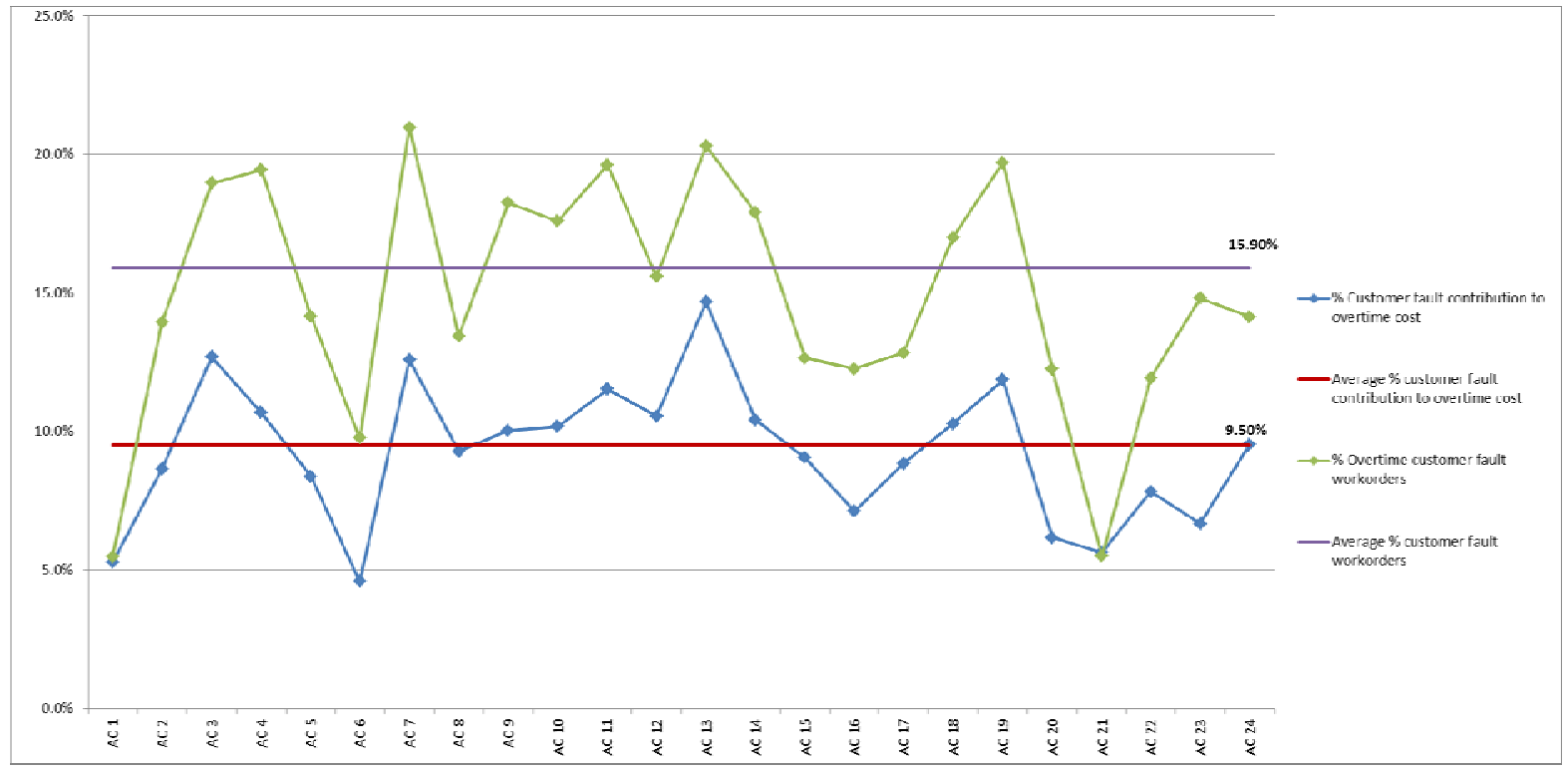

Fig. 6. Overtime: \% customer side fault cost contribution vs \% customer side faults per AC for 2014-2015

\section{Discussion}

The discussion section examines the origin of the incorrect transactional data embedded in the ESP call quality and observe how it manifests as such in terms of customer side faults downstream. The effect of the incorrect transactional data on the AC's overtime will then be considered to determine the cost implications thereof.

The national call quality on ESP calls depicts an average for all the call centres combined to be $75 \%$ 
(see Table 1). Thus, $25 \%$ of the calls do not adhere to the prescribed call quality standards and this signifies possible problems with transactional data capturing. This notion is further strengthened by the fact that for the financial year of 2014-2015, $19.2 \%$ of all the workorders in Figure 1 and $15.9 \%$ of overtime workorders in Figure 2 are marked as customer faults, and in this case customer faults indicate incorrect transactional data. The increased expenditure on customer side faults is indicative of how the low integrity of data (in this case, contaminated transactional data) shapes the quality of decision making processes about recurrent expenditure and, ultimately, the relative efficiency of the organizations (Vosberg \& Kumar, 2001; Sheng \& Mykytyn, 2008; Banasiewicz, 2013). As firms increasingly depend on transactional business databases to conduct their business operations and execute solid business decisions to improve firm performance; the quality of transactional data flowing in the firms' information system has a substantial impact on business decisions, operations, quality of services and firm performance achieved (Sheng \& Mykytyn, 2008). Consistent with the Resource Based View's argument that superior resources are more 'efficient' in that they enable a firm to produce more economically and/or better satisfy customer wants" (Peteraf and Barney, 2003, p. 311; Bridoux, 2004), the use of contaminated transactional data may not only compromize the LEU's superior performance in power generation, but also may result in unwarranted or wasteful expenditure.

Due to a lack of historical data on the call quality of ESP from the call centres, the customer fault contribution to the total amount of faults was analyzed to determine the quality of transactional data capturing over the years. The yearly rise in the customer side faults vs valid ESP faults in Table 2 as well as the increase in the percentage of customer side faults vs valid ESP faults in Figure 1 and Figure 2 imply degradation in the quality of transactional data quality on a year to year basis. Similarly gradual master data quality degradation is a known occurrence in medium to large organizations due to system complexities and human error (Freeform dynamics, 2013a, p. 2). A consequence of the yearly rise in the amount of customer side faults is depicted in Figure 3 as a yearly cost increase in the overtime costs related to customer side faults. The consonance of increases in customer side faults and increases on overtime costs resonates with Vosburg and Kumar's (2001) claim that as the size and complexity of the business increases, recovering data integrity may be difficult or impossible. They, therefore, elaborate on the essence of users of transactional data and planning systems' understanding of the origins and effects of dirty data and devising systematic safeguards of preventing contamination of such data. This finding further buttress Mitra and Chaya's (1996) finding on the lack of evidence to support the claim that investment in information technology reduces labour costs in organizations.

Although the Resource Based View presents assets and strengths such as information and organizational processes as key enablers of planning and implementation strategies that improve its organizational efficiency (see Barney, 1991; Robinson, 2008); the LEU's use of information technology to identify the volume of customer side faults and, hence, reduce wasteful expenditure (through ignoring customer side faults) has not improved the unwarranted expenditure of this LEU. Although this energy utility still enjoys unfair advantage through its monopoly of energy production and distribution (an element of rareness and inimitability according to RBV), unwarranted expenditure seem go unabated, because it is in the technicians and engineers' interest to attend to customer side faults, as it increases their overtime wages). What is clear from this contradiction between use of technology to identify economic leakages (e.g., customer side faults) and continued ballooning of the wage bill is that IT assets and resources in themselves were not the bases of establishing "rarity", but rather they become sources of competitive advantage when they combined with other factors within the firm to create source of competitive advantages and barriers to imitation or duplication (see April, 2004; Ramorena, 2016)

Each AC has a unique contribution to the total overtime costs of customer side faults as shown in Figure 4. In Figure 5, the relationship between the amount of customer side faults vs overtime costs related to these faults differs per AC. The lack of a direct overall correlation between the amount of customer side fault workorders during overtime and the overtime costs for these workorders can be attributed to the fact that more than one resource can work on a workorder and time in terms of travel and fault finding can vary per workorder. As Ranjan, Goyal and Ahson (2008) suggest, while a deep understanding of knowledge hidden in transactional data processing is critical to organizational decision making and promoting the firm's competitive position, analyzing the sources, relationships and patterns of such transaction data is rare. When comparing the overtime customer side fault workorder $\%$ to the cost impact these workorders have on overtime per AC (see Figure 6), there is also a lack of a direct correlation although the trend indicates a modest correlation between the 2 
variables. In the absence of clearly identifiable relationships between customer side faults and expenditure, data mining could provide a useful starting point for understanding existing patterns in the data. Ranjan, Goyal and Ahson (2008) observe that data mining serves as a vital tool for making sense of quantifiable transactional data, discovering and extracting observable patterns from this data as a basis for correcting anomalies and inconsistencies and improved data driven decision making. Consistent with the Resource Based View, if the LEU were to maintain some systematic differences within the energy industry with respect to the resources (e.g., how it uses information technology to reduce unwarranted expenditure and improve its competitive advantage in the energy sector) it controls (i.e., firm resource heterogeneity) (Barney, 1991; Robinson, 2008), then, it would maximize its competitive edge in relations to its rivals.

Despite the fact that a direct correlation does not exist between the amount of overtime customer side fault workorders and the contribution it makes to overtime costs of the ACs in Fig. 7, the effects of the possible transactional data quality issues contained in the $25 \%$ of Table 1, are expressed in the incorrect transactional data of $19.2 \%$ in Fig. 1 and $15.9 \%$ in Fig. 2. The complexity of determining the relation between these two variables could be attributed LEU's ways of capturing, processing, documenting, and the resultant availability of such data on business transactions. Banasiewicz (2013) argues that while transactional data crunching capabilities evolve in response to organizational priorities and the growth in the availability of data, the expansion of resultant data analytic capabilities will be skewed across organizations, creating competitive disparities in terms of more advanced data analytical competencies due to variance in organizational priorities.

The cost impact of the incorrect transactional data when averaged for all ACs amounts to a 9.5\% contribution of the 2014-2015 overtime costs in Fig. 6. The $9.5 \%$ is unnecessary expenditure on the overtime wage bill for 2014-2015 and confirms the notion that poor quality data manifests as increases in costs (Sadiq, 2013, p. 77). This unwarranted expenditure has a negative effect on LEU's efforts to achieve the savings in costs, as mandated by its Government (Department of Public Relations, 2014, p. 1). The $9.5 \%$ expenditure also presents a significant savings opportunity, as it coheres with the Global data quality research of 2015 , where $92 \%$ of companies believed that by achieving data of the highest quality, unwarranted costs would be reduced resulting in profits increases of an average of $15 \%$ (Experian data quality, 2015, p. 4).

\section{Recommendations}

Based on the ensuing discussion the following recommendations are made:

9.1. Transactional data authentication. Stronger emphasis on pre-determining and authenticating the veracity of extracted transactional data during ESP calls, especially the identification of customer side, has the potential to reduce expenditure on overtime for forced outages by $9.5 \%$, contributing to significant cost savings.

9.2. ESP call quality KPI breakdown. The transactional data component within the ESP call quality key performance indicator (KPI) should be displayed as a sub KPI. The sub KPI will allow better tracing of the effects of incorrect transactional data originating from the call centre and can assist the business to isolate the portion of the sub KPI responsible for customer side faults.

9.3. Awareness on the cost impact of incorrect transactional data. LEU call centre personnel, technicians and middle line managers need to be sensitized on the cost impact of incorrect transactional data to broaden awareness and deepen individual ownership among employees on the transactional data they are involved with.

\section{Implications for further research}

10.1. Impact on other areas. Future studies should examine the impact of incorrect transactional data on other areas of LEU's business such as technician's travelling costs, opportunity costs of time lost during travel to resolve unwarranted queries (i.e., the volume of productive work generated if technicians attended to genuine queries exclusively) and the impact of attending to erroneous queries on a technicians' morale and customer satisfaction.

10.2. Correlation between the percentage of incorrect transactional data records and cost. Future studies could explore the correlation between the percentage of incorrect transactional data records and the cost on the business component influenced by the data. This could be tested per department within the same company, within different companies involved in the same industry and within different industries.

10.3. Cost impact between different types of incorrect data. Compare the cost impact between incorrect master and incorrect transactional data. The mistaken assumption is probably that master data have a big impact on organizational competitiveness, while transactional data have a negligible impact and, hence, tend to be ignored. 
The cost implications of both transactional and master data need to be examined both separately and in conjunction with each other.

\section{Conclusion}

The case study on LEU Province A uncovered the nature and extent of accuracy of transactional customer data and determined its impact on recurrent expenditure, particularly the overtime wage bill for forced outages. Although the accuracy of transactional customer data was not unambiguously available from the customer centre KPIs, it was included as a $70 \%$ contribution to the ESP call quality KPI. This latest KPI for the financial year 2014-2015 indicated that $25 \%$ of the calls did not adhere to the expected LEU standard, which indicated possible transactional data challenges. One issue which was caused by and identified with incorrect transactional data in the field services environment was the forced outages, which were marked as customer side faults. For each consecutive year tested, an increase in customer side fault volumes triggered an increase in the percentage contribution to the total amount of forced outages and overtime cost. An evaluation of the 2014-2015 financial year uncovered that $19.2 \%$ of all forced outages and $15.9 \%$ of overtime forced outages were marked as customer side faults. The $15.9 \%$ customer side faults revealed a 9.5\% contribution to overtime costs, which uncovered a unique saving opportunity. It was, then, recommended that pre-determining and authenticating the veracity of transactional data extracted from customers during ESP calls, especially the identification of customer side faults could reduce expenditure on overtime. The cost savings in terms of overtime can assist LEU to achieve the savings and operational efficiency mandated by its country's government. A further recommendation was to specifically have a KPI available at the Contact centres (i.e., the nerve centre) that only dealt with transactional data, to assist LEU customer divisions to uncover other costs and areas impacted negatively by incorrect transactional data. By creating awareness across all levels of business on the impact of incorrect transactional data, ownership among employees can be instilled on the transactional data they are involved with and highlight the importance of data accuracy.

\section{Acknowledgements}

The researchers are very grateful to the LEU personnel for availing customer data and rendering its meaningful interpretation, in spite of their hectic schedules. The researchers' families are strongly acknowledged for their patience, support and understanding. To God be all the glory for giving the researchers the wisdom, ability and opportunity to conduct this research.

\section{References}

1. Afalciano. (2014). Stock exchange - Geographic information systems. Available at: http://gis.stackexchange.com/questions/88484/excel-distance-calculation. Accessed on 4 March.

2. April, K.A. (2004). A Resource-Based View of the Firm: Integrating the Role of IT as a Strategic Resource-An Empirical Study of South African Personal Financial Services (Assurance) Firms (1999-2003). PhD Thesis, Graduate School of Business, University of Cape Town.

3. Banasiewicz, A. (2013). Marketing Database analytics: Transforming data for competitive advantage. New York: Routledge.

4. Barnard. (2013). IEP. Available at: URL MASKED. Accessed on 25 October.

5. Barney, J. (1991). Firm Resources and Sustained Competitive Advantage, Journal of Management, 17 (1), pp. 99-120.

6. IL and BJM. (2012). Estimating the price flexibility for Energy by Province in Country, Country Journal of Sciences for Economic management, 10 (10), pp. 400-405.

7. Borek, A. et al. (2014). Total information risk management: Maximizing the value of data and information asses. Waltham: Elsevier.

8. Bridoux, F. (2004). A resource-based approach to performance and competition: An overview of the connections between resources and competition. Institut d'Administration et de Gestion, Université catholique de Louvain, Belgium.

9. Chen, W.J. et al. (2013). A practical guide to managing reference data with IBM InfoSphere master data management reference data management hub. Redbooks.

10. Cohen, L., Manion, L. and Morrison, K. (2011). Research Methods in Education. $7^{\text {th }}$ ed. New York: Routledge.

11. Collin, P.H. (2006). Dictionary of Economics: Over 3,000 terms clearly defined. $2^{\text {nd }}$ ed. London: Bloomsbury.

12. Deloitte. (2013). Independent Economic Studies. Available at: URL Masked. Accessed on 25 October.

13. Department of Public Relations. (2014). Statement. Available at: URL Masked.

14. Eckerson, W. (2002). Data quality and the bottom line. Achieving business success through a commitment to high quality data. United States: 101communications LLC.

15. ED. (2013). Energy Department decision on LEU application. Available at: URL Masked.

16. Energy Department. (2015). Energy Department: Alternative energy suppliers. Available at: URL Masked.

17. Energy Department. (2011b). Expansion plan. Available at: URL Masked. Accessed on 25.03. 
18. Energy Department. (2011a). FAQ's. Available at: URL Masked. Accessed on 6 March.

19. Energy Department. (2009). Price ruling and policy. Available at: URL Masked.

20. Energy Department. (1998). Statutes and Legislation. Available at: URL Masked.

21. Experian Data Quality. (2015). Global Data Quality Research Discussion Paper 2015. Available at: https://www.edq.com/globalassets/uk/papers/global-research-2015_20pp-ext-apr15.pdf.

22. Farquhar, J.D. (2012). Case Study Research for Business. $1^{\text {st }}$ ed. London: Sage publications.

23. Ministry of Finance. (2015). Files. Available at: URL Masked.

24. Freeform Dynamics. (2013b). Customer Data Quality in Context A Business Perspective. Available at: http://www.freeformdynamics.com/fullarticle.asp?aid=1725\&searchFor=.

25. Freeform Dynamics. (2013a). Managing customer data quality. A view for IT leaders and Architects. Available at: http://www.freeformdynamics.com/fullarticle.asp?aid=1726.

26. Shelly, G. and Gunter, R. (2012). Teachers Discovering Computers: Integrating Technology in a Connected World. $7^{\text {th }}$ ed. Boston, USA: Course Technology.

27. Hassanien, A.E. et al. (2015). Big Data in Complex Systems: Challenges and Opportunities. London: Springer.

28. Haug, A., Zachariassen, F. and Van Liempd, D. (2011). The costs of poor data quality, Journal of industrial engineering and management, 4 (2), pp. 168-193.

29. Kozlenkova, I.V., Samaha, S.A. and Palmatier, R.W. (2014). Resource-based theory in marketing, Journal of the Academy of Marketing Science, 42 (1), pp. 1-21.

30. Large Energy Utility. (2015d). ESP Inbound Processes. Available at: URL Masked.

31. Large Energy Utility. (2015e). Integrated report. LEU. Available at: URL Masked.

32. Large Energy Utility. (2015a). LEU Company Information. Available at: URL Masked.

33. Large Energy Utility. (2013a). LEU first Decade. Available at: URL Masked.

34. Large Energy Utility. (2014b). LEU forego bonus. Available at: URL Masked.

35. Large Energy Utility. (2013b). Mandate, Vision, Mission, Strategy. Available at: URL Masked. Accessed on 08.12.

36. Large Energy Utility. (2011). Media Statement 27 June 2011. Available at: URL Masked. Accessed on 27 June.

37. Large Energy Utility. (2014a). Tariff history. Available at: URL Masked. Accessed on 4 June.

38. Large Energy Utility. (2015b). Wheeling of Energy. Available at: URL Masked.

39. Large Energy Utility (2015c). Year Celebrations. Available at: URL Masked. Accessed on 01 May.

40. MCD. (2009). Energy Capitalism in Africa. African Country: African Country Press.

41. McIvor, R. (2005). The Outsourcing Process: Strategies for Evaluation and Management. Cambridge, University press.

42. Mitra, S. and Chaya, A. (1996). Analyzing Cost-Effectiveness of Organizations: The Impact of Information Technology Spending, Journal of Management Information Systems, 13 (2), pp. 29-57.

43. Nothnagel, K. (2008). Empirical Research within Resource-Based Theory: A Meta-Analysis of the Central Propositions. Germany: Springer Science \& Business Media.

44. Peteraf, M. and Barney, J. (2003). Unraveling the resource-based tangle, Managerial and Decision Economics, 24, pp. 309-323.

45. Ramorena, M. (2016). Impact of social networks on innovation, competitiveness and firm performance in the South African context: A case study of emerging construction firms in the Free State. Central University of Technology, Free State.

46. Ranjan, J., Goyal, D. and Ahson, S. (2008). Data mining techniques for better decisions in human resource management systems, International Journal of Business Information Systems, 3 (5), pp. 464-481.

47. Reid, A. and Catterall, M. (2005). Invisible data quality issues in a CRM implementation, Journal of Database Marketing \& Customer Strategy Management, 12 (4), pp. 305-314.

48. Robinson, S. (2008). Understanding the Resource Based View: Implications of methodological choice and a new creative context. PhD Thesis, Queensland University of Technology.

49. Sadiq, S. (2013). Handbook of data quality: Research and practice. $1^{\text {st }}$ ed. Brisbane: Springer.

50. Sheng, Y. and Mykytyn, P. (2008). Information technology investment and firm performance: A perspective of data quality. Proceedings of the Seventh International Conference on Information Quality (ICIQ-02, pp. 132-141).

51. State Commission. (2015). Expansion Plan. Available at: URL Masked. Accessed on 15.08.

52. Statistics of Country. (2014). Public access documents. Available at: URL Masked. Accessed on 26.06.

53. Vosberg, J. and Kumar, A. (2001). Managing dirty data in organizations using ERP: Lessons from a case study, Industrial Management \& Data Systems, 101 (1), pp. 21-31.

54. Wang, Xiaohu et al. (2005). Information Quality. New York: Routledge. 